\title{
FONTES DE ENXOFRE NO CONTROLE DO PERCEVEJO-PRETO, CYRTOMENUS MIRABILIS (PERTY, 1836) (HEMIPTERA: CYDNIDAE) EM AMENDOIM
}

\author{
Paulo Cesar Polli Junior ${ }^{1}$, Rodolfo de Oliveira Rincão, Maycon Ferraz, Rogério Soares de Freitas, \\ Ignácio José Godoy e Marcos Doniseti Michelotto
}

${ }^{1}$ Graduando em Agronomia, Bolsista Fundag/Apta, Unirp, São José do Rio Preto, SP

RESUMO: O presente estudo teve como objetivo avaliar o efeito de fontes de enxofre no controle do percevejo-preto, Cyrtomenus mirabilis (Perty, 1836) (Hemiptera: Cydnidae) em amendoim. O experimento foi instalado em área experimental da Apta/Polo Centro Norte, em Pindorama, na safra 2018/19. As fontes de enxofre utilizadas foram o Gesso Agrícola (150 kg de $\mathrm{SO}_{4}{ }^{2-}$ tonelada $^{-1}$ ) e o Sulfurgran $90 ®$ (contendo 90\% de enxofre elementar na forma de pastilhas). Aos 130 DAS avaliou-se o número de ninfas e adultos do percevejo através de trincheiras e o percentual de grãos atacados. Apesar da baixa infestação do percevejo-preto no experimento é possível concluir que o produto Sulfurgran $90 \AA$ (enxofre $90 \%$ pastilhado) na dosagem de $70 \mathrm{~kg} \mathrm{ha}^{-1}$ misturado ao adubo na semeadura reduz o número de percevejo-preto e os danos ocasionados aos grãos de amendoim podendo ser utilizado preventivamente.

Palavras-Chave: Arachis hypogaea L., IAC OL3, praga-de-solo.

\section{INTRODUÇÃO}

O percevejo-preto, Cyrtomenus mirabilis (Perty, 1830) (Hemiptera: Cydnidae), possui distribuição em praticamente toda a América continental, desde os Estados Unidos até o Uruguai e Argentina, sendo considerada uma espécie importante nas culturas de amendoim no Peru, Paraguai, Argentina e Brasil (FROESCHNER 1960, GALLO et al. 2002).

$\mathrm{O}$ adulto de $C$. mirabilis e suas fases jovens vivem no solo, incluindo sua oviposição. Em amendoim, seus danos estão relacionados ao ataque em vagens na fase de desenvolvimento dos grãos, na qual ninfas e adultos inserem o estilete de seu aparelho bucal, atingindo os grãos em desenvolvimento. Ao se alimentarem dos grãos, os mesmos tornam-se manchados impróprios para comercialização (RIIS et al., 2005).

Dessa forma torna-se importante a busca por alternativas de controle, de fácil adoção pelos produtores e que causem o menor impacto possível ao meio ambiente e aos consumidores. Até o momento não há inseticidas registrados para o controle desta praga em amendoim para as nossas condições. Nos Estados Unidos, uma das poucas opções de inseticida para controle de Pangaeus bilineatus (Say) que causa similar em amendoim é o clorpirifós (Lorsban® ${ }^{\circledR}$ 15G, na dosagem de 2,24 


\section{Encontro Sobre a Cultura do Amendoim \\ 15 a 17 de agosto de 2019 na Estação de Eventos Cora Coralina e FCAV/UNESP, Jaboticabal-SP}

$\mathrm{kg}$ de i.a. $\mathrm{ha}^{-1}$ ) na fórmula granulada, aplicado em faixa sobre as plantas de amendoim (CHAPIN, THOMAS, 2003).

Uma das alternativas possíveis é a utilização do enxofre como repelente a determinados insetos-praga. Segundo Nascimento et al. (2014), aplicações de fontes de enxofre como o gesso agrícola ou adubos sulfurados, sulfato de cálcio e sulfato de amônio promoveram a tolerância das plantas de algodoeiro ao ataque do percevejo-castanho, Scaptocoris sp. (Hemiptera: Cydnidae), apesar de não promoveram redução populacional da praga.

Como o percevejo-preto é da mesma família do percevejo-castanho, existe a possibilidade de que o uso de enxofre também possa atuar como repelente desta praga em amendoim. Dessa forma, o objetivo deste foi avaliar o efeito de fontes de enxofre no controle do percevejo-preto, Cyrtomenus mirabilis (Perty, 1836) (Hemiptera: Cydnidae) em amendoim.

\section{MATERIAL E MÉTODOS}

O experimento foi instalado em área experimental da Apta/Polo Centro Norte, em Pindorama, na safra 2018/19, em local com histórico de ocorrência do inseto em safras anteriores.

O delineamento experimental adotado foi em blocos casualizados, com 4 repetições e os tratamentos são apresentados na Tabela 1.

Tabela 1. Fontes de enxofre, dosagens, modo e época de aplicação para controle do percevejo-preto (C. mirabilis) em comparação com o inseticida Regent Duo que possui eficácia de controle.

\begin{tabular}{|c|c|c|c|c|}
\hline Tratamento & $\begin{array}{c}\text { Dose } \\
\left(\mathrm{g} \mathrm{de} \mathrm{i.a.} \mathrm{ha}^{-1}\right) \\
\end{array}$ & $\begin{array}{c}\text { Dose } \\
\left(\mathrm{L} / \mathrm{Kg} \mathrm{p} \text {.c. } \mathrm{ha}^{-1}\right) \\
\end{array}$ & Modo de Aplicação & Época de aplicação \\
\hline 1. Testemunha & - & - & & - \\
\hline 2. Regent ${ }^{\circledR}$ Duo & $180+120$ & 2,0 & Sulco & Semeadura \\
\hline 3. Gesso Agrícola & 150.000 & 1.000 & Lanço na superfície & Semeadura \\
\hline 4. Gesso Agrícola & 225.000 & 1.500 & Lanço na superfície & Semeadura \\
\hline 5. Sulfurgran $90 \AA$ & 63.000 & 70 & $\begin{array}{l}\text { Misturado ao adubo } \\
\text { de semeadura }\end{array}$ & Semeadura \\
\hline 6. Sulfurgran 90® & 63.000 & 70 & Lanço na superfície & $30 \mathrm{DAS}$ \\
\hline
\end{tabular}

Cada parcela foi constituída de quatro linhas de 4 metros de comprimento, com espaçamento entre linhas de 0,9m. A semeadura foi realizada manualmente no dia 29/10/2018 e na densidade de 20 sementes por metro, utilizando a cultivar IAC OL3. As sementes foram previamente tratadas com fungicida registrado para controle de doenças redutoras de estande.

A adubação de base utilizada foi de $250 \mathrm{~kg} \mathrm{ha}^{-1}$ do produto formulado 05-30-10 conforme recomendações da cultura (Godoy et al., 2014). As fontes de enxofre utilizadas no experimento foram o Gesso Agrícola contendo em sua composição $150 \mathrm{~kg}$ de $\mathrm{SO}_{4}{ }^{2-}$ por tonelada e o Sulfurgran 90® 


\section{Encontro Sobre a Cultura do Amendoim \\ 15 a 17 de agosto de 2019 na Estação de Eventos Cora Coralina e FCAV/UNESP, Jaboticabal-SP}

(Produquímica Agro) contendo 90\% de enxofre elementar na forma de pastilhas e que tem como característica a liberação lenta.

A testemunha positiva (padrão de controle) utilizada foi o inseticida Regent ${ }^{\circledR}$ Duo da Basf (fipronil a 180 g i.a. + alfacipermetrina a $120 \mathrm{~g}^{\text {i.a. }}$ Litro ${ }^{-1}$ ) aplicado via drench sobre as sementes no sulco de semeadura com pulverizador costal elétrico, dotado de ponta de pulverização do tipo leque e com volume de 100 litros ha ${ }^{-1}$. O produto Regent ${ }^{\circledR}$ Duo foi utilizado, por ter apresentado eficácia de controle em experimentos anteriores (dados não publicados).

Aos 130 DAS, para a quantificação dos percevejos no solo, em cada parcela foi aberta uma trincheira de $0,5 \mathrm{~m}$ de comprimento $\mathrm{X} 0,3 \mathrm{~m}$ de largura $\mathrm{X} 0,15 \mathrm{~m}$ de profundidade, utilizando uma forma e enxadões. O solo coletado foi cuidadosamente inspecionado com o auxílio de água e peneiras e os percevejos presentes foram separados, contados e categorizados em adultos e ninfas.

Concomitantemente, foi realizada a amostragem de $0,5 \mathrm{~m}$ de linha de plantas, e avaliadas quanto ao número de vagens, grãos e grãos apresentando sinais de ataque do percevejo.

Os dados de contagem dos danos foram submetidos à análise de variância pelo teste $\mathrm{F}$ e as médias comparadas pelo teste Tukey a $10 \%$ de probabilidade. A eficiência dos inseticidas testados foi calculada utilizando a fórmula de Abbott (1925), descrita a seguir: $\mathrm{EC}(\%)=\left[\left(\% \mathrm{M}_{\text {tra }}-\% \mathrm{M}_{\text {test }}\right) /(100-\right.$ $\left.\% \mathrm{M}_{\text {test }}\right)$ ] x 100 , onde: $\mathrm{EC}(\%)=$ Eficiência de Controle, $\mathrm{M}_{\text {trat }}=$ Mortalidade do tratamento e $\mathrm{M}_{\text {test }}=$ Mortalidade na testemunha

\section{RESULTADOS E DISCUSSÃO}

O número de ninfas diferiu entre os tratamentos avaliados, sendo a maior ocorrência observada no tratamento de gesso na dosagem de $1.000 \mathrm{~kg} \mathrm{ha}^{-1}$ e menor no tratamento inseticida onde não se observou a presença de ninfas (Tabela 2). A testemunha e os demais tratamentos ficaram na posição intermediária. $\mathrm{O}$ fato de a testemunha ter apresentado número de insetos menor que outros tratamentos ocorre quando a infestação não é uniforme na área.

O número de adultos amostrados foi baixo, variando de 0,0 a 1,5 por trincheira, não diferindo entre os tratamentos. Dessa forma, o total de percevejos por trincheira seguiu o mesmo padrão observado para as ninfas (Tabela 2).

Apesar da baixa infestação, observou-se resultados interessantes em relação à eficiência de controle (Tabela 2). O tratamento inseticida apresentou a mais alta eficiência de controle e o tratamento Sulfurgran $90 \AA$ utilizado misturado ao Adubo de semeadura apresentou eficiência de $42,9 \%$ indicando algum controle do inseto.

Tabela 2. Número de ninfas, adultos e totais de percevejo-preto e eficiência de controle (\%) em função das fontes de enxofre utilizadas, em comparação ao inseticida Regent ${ }^{\circledR}$ Duo considerado padrão de controle no experimento. Pindorama, SP, safra 2018/19. 
XVI Encontro Sobre a Cultura do Amendoim

15 a 17 de agosto de 2019 na Estação de Eventos Cora Coralina e FCAV/UNESP, Jaboticabal-SP

\begin{tabular}{|c|c|c|c|c|}
\hline \multirow{2}{*}{ Tratamentos } & Ninfa & Adulto & Total & \multirow{2}{*}{$\begin{array}{l}\text { Eficiência de Controle } \\
\qquad(\%)\end{array}$} \\
\hline & \multicolumn{3}{|c|}{--------------Número/trincheira------------ } & \\
\hline 1. Testemunha & $3,0 \mathrm{ab}$ & 0,5 & $3,5 \mathrm{ab}$ & - \\
\hline 2. Gesso 1.000 & $15,5 \mathrm{a}$ & 1,5 & $17,0 \mathrm{a}$ & 0,0 \\
\hline 3. Gesso 1.500 & $3,0 \mathrm{ab}$ & 0,8 & $3,8 \mathrm{ab}$ & 0,0 \\
\hline 4. Sulfurgran $90 ® 30 \mathrm{DAS}$ & $2,5 \mathrm{ab}$ & 0,8 & $3,3 \mathrm{ab}$ & 7,1 \\
\hline 5. Sulfurgran $90 \AA+$ Adubo & $2,0 \mathrm{ab}$ & 0,0 & $2,0 \mathrm{ab}$ & 42,9 \\
\hline 6. Regent $®$ Duo & $0,0 \quad \mathrm{~b}$ & 0,0 & $0,0 \quad b$ & 100,0 \\
\hline Média & 4,33 & 0,58 & 4,92 & \\
\hline Teste F & $2,15^{*}$ & $1,46^{\mathrm{ns}}$ & $2,13^{*}$ & \\
\hline C.V. $(\%)$ & 75,72 & 41,87 & 74,78 & \\
\hline
\end{tabular}

DAS= Aplicação do produto sobre as plantas aos 30 dias após a semeadura; Médias seguidas de mesma na coluna não diferem entre si pelo teste de Tukey a $10 \%$ de probabilidade.

Com relação ao percentual de grãos de amendoim com sinais de alimentação do percevejopreto não observou-se diferença significativa entre os tratamentos variando de 1,0 (Regent ${ }^{\circledR}$ Duo) a 9,2 (Gesso na dosagem de $1.000 \mathrm{~kg} \mathrm{ha}^{-1}$ ), conforme Tabela 3.

No entanto, quando se observou a eficiência de redução dos danos em relação à testemunha, com exceção do Gesso na dosagem de $1.000 \mathrm{~kg} \mathrm{ha}^{-1}$, todos os outros tratamentos reduziram os danos do percevejo, com destaque para os tratamentos Regent ${ }^{\circledR}$ Duo $(82,7 \%)$ e Sulfurgran $90 \AA$ + Adubo $(69,1)$ (Tabela 3).

Tabela 3. Número de ninfas, adultos e totais de percevejo-preto e eficiência de controle (\%) em função das fontes de enxofre utilizadas, em comparação ao inseticida Regent ${ }^{\circledR}$ Duo considerado padrão de controle no experimento. Pindorama, SP, safra 2018/19.

\begin{tabular}{lcccc}
\hline \multicolumn{1}{c}{ Tratamentos } & $\begin{array}{c}\text { Grãos com Danos } \\
(\%)\end{array}$ & $\begin{array}{c}\text { Eficiência de } \\
\text { Redução no dano } \\
(\%)\end{array}$ & $\begin{array}{c}\text { Estande Final } \\
\left(\text { plantas }{ }^{-1}\right)\end{array}$ & $\begin{array}{c}\text { Produtividade } \\
\left(\mathrm{kg} \mathrm{ha}^{-1}\right)\end{array}$ \\
\hline Testemunha & 5,8 & - & $10,7 \mathrm{ab}$ & $3.888,90$ \\
Gesso 1.000 & 9,2 & 0,0 & $9,4 \mathrm{~b}$ & $3.704,80$ \\
Gesso 1.500 & 2,9 & 50,7 & $12,2 \mathrm{a}$ & $3.784,70$ \\
Sulfurgran 90® 30DAS & 3,4 & 42,4 & $10,9 \mathrm{ab}$ & $3.881,90$ \\
Sulfurgran 90® + Adubo & 1,8 & 69,1 & $9,1 \mathrm{~b}$ & $4.364,50$ \\
Regent ${ }^{\circ}$ Duo & 1,0 & 82,7 & $12,6 \mathrm{a}$ & $4.253,40$ \\
\hline Média & 4,00 & & 10,83 & $3.979,70$ \\
\hline Teste F & $2,07^{\text {ns }}$ & & $4,86^{* *}$ & $0,58^{\text {ns }}$ \\
\hline C.V & 47,29 & 5,71 & 9,48 \\
\hline
\end{tabular}

Médias seguidas de mesma na coluna não diferem entre si pelo teste de Tukey a 5\% de probabilidade. 


\section{Encontro Sobre a Cultura do Amendoim}

15 a 17 de agosto de 2019 na Estação de Eventos Cora Coralina e FCAV/UNESP, Jaboticabal-SP

Apesar de diferenças significativas em relação ao estande final de plantas, não foram constatadas diferenças significativas na produtividade de vagens $\left(\mathrm{kg} \mathrm{ha}^{-1}\right)$ indicando que os tratamentos utilizados não afetam de forma significativa a produtividade (Tabela 3).

Embora o inseticida tenha apresentado excelente eficiência de controle do percevejo-preto, é preciso ressaltar que seu uso na dosagem avaliada deixa resíduo do ingrediente ativo fipronil nos grãos de amendoim atingindo o Limite Máximo de Resíduo permitido e portanto novos estudos deverão ser realizados para identificar doses seguras para seu uso.

\section{CONCLUSÕES}

Apesar da baixa infestação do percevejo-preto no experimento é possível concluir que o produto Sulfurgran $90 \AA$ (enxofre $90 \%$ pastilhado) na dosagem de $70 \mathrm{~kg} \mathrm{ha}^{-1}$ misturado ao adubo na semeadura reduz o número de percevejo-preto e os danos ocasionados aos grãos de amendoim podendo ser utilizado preventivamente.

\section{AGRADECIMENTOS}

Os autores agradecem as Empresas Balsamo, Beatrice, Copercana, Coplana, Mars Brasil e Terra Nuts pelo aporte financeiro ao projeto através da Fundag.

\section{REFERENCIAS BIBLIOGRÁFICAS}

CHAPIN, J.W.; THOMAS, J.S. Burrower bugs (Heteroptera: Cydnidae) in peanut: Seasonal species abundance, tillage effects, grade reduction effects, insecticide efficacy, and management. Journal of Economic Entomology, v.96, n.4, p.1142-1152, 2003.

FROESCHNER, R.C. Cydnidae of the Western Hemisphere. Proceedings of the United States National Museum, v.111, p.337-680, 1960.

GALLO, D.; NAKANO, O.; NETO, S.S.; CARVALHO, R.P.L.; BAPTISTA, G.C.; FILHO, E.B.; PARRA, J.R.P.; ZUCCHI, R.A.; ALVES, S.B.; VENDRAMIM, J.D.; MARCHINI, L.C.; LOPES, J.R.S.; OMOTO, C. Entomologia agrícola. 10.ed. Piracicaba: FEALQ, 2002. 920p.

GODOY, I.J.; BOLONHEZI, D.; MICHELOTTO, M.D.; FINOTO, E.L.; KASAI, F.S.; FREITAS, R.S. Amendoim - Arachis hypogaea L. In: AGUIAR, A.T.E.; GONÇALVES, C.; PATERNIANI M.E.A.G.Z.; TUCCI, M.L.S.; CASTRO, C.E.F. (Eds.). Instruções agrícolas para as principais culturas econômicas. $7^{\text {a }}$ Ed. rev. e atual. Campinas: Instituto Agronômico, 2014. p. 22-27p. (Boletim IAC, $\left.n^{\circ} 200\right)$.

NASCIMENTO, V.L.; MIRANDA, J.E.; MALAQUIAS, J.B.; CARVALHO, M.C.S.; LINS, L.C.P.; PANIAGO, J. Sulphur sources on the management of Scaptocoris castanea (Hemiptera: Cydnidae) on cotton. Revista Colombiana de Entomología, v.40, n.1, p.15-20, 2014. 
XVI Encontro Sobre a Cultura do Amendoim

15 a 17 de agosto de 2019 na Estação de Eventos Cora Coralina e FCAV/UNESP, Jaboticabal-SP

RIIS, L.; BELOTTI, A.C.; ARIAS, B. Bionomics and population growth statistics of Cyrtomenus bergi (Hemiptera: Cydnidae) on different host plants. Florida Entomologist, v.88, p.1-10, 2005. 